\title{
How do parent-child interactions predict and maintain depression in childhood and adolescence? A critical review of the literature
}

Article

Accepted Version

Chapman, R., Parkinson, M. and Halligan, S. (2016) How do parent-child interactions predict and maintain depression in childhood and adolescence? A critical review of the literature. Adolescent Psychiatry, 6 (2). pp. 100-115. ISSN 2210-6766 doi: https://doi.org/10.2174/2210676606666160822101450 Available at https://centaur.reading.ac.uk/66971/

It is advisable to refer to the publisher's version if you intend to cite from the work. See Guidance on citing.

To link to this article DOI:

http://dx.doi.org/10.2174/2210676606666160822101450

Publisher: Bentham Science Publishers

All outputs in CentAUR are protected by Intellectual Property Rights law, including copyright law. Copyright and IPR is retained by the creators or other copyright holders. Terms and conditions for use of this material are defined in the End User Agreement. 


\section{CentAUR}

Central Archive at the University of Reading

Reading's research outputs online 
Running head: PARENT-CHILD INTERACTIONS AND CHILD DEPRESSION

How Do Parent-Child Interactions Predict and Maintain Depression in Childhood and Adolescence? A Critical Review of the Literature

\author{
Rosanna Chapman ${ }^{1}$, Monika Parkinson* \& Sarah Halligan ${ }^{1}$ \\ ${ }^{1}$ Department of Psychology, University of Bath, Bath, United Kingdom
}

Received: June 19, 2016

Revised: August 2, 2016

Accepted: August 4, 2016

*Address correspondence to this author at:

School of Psychology and Clinical Language Sciences, University of Reading, Reading, RG6

6AL, United Kingdom.

Phone: 01183786667

Email: m.b.parkinson@,reading.ac.uk 


\begin{abstract}
Background and Objective: Negative parent-child interaction patterns have been linked to youth depression, with a causal influence being assumed. However, the majority of empirical studies examining this issue have used self-report methods to assess parent-child relationships, which cannot capture the temporal dynamics of dyadic interactions and may be subject to reporting bias. This review considers the association between parent-child interactions and youth depression with a specific focus on observational methodology.

Method: A literature search was conducted including studies that investigated the association between observed parent-child interactions and youth depressive symptomology. Literature was obtained using database searches, citation searches and screening of recent reviews.

Results and Conclusion: Maternal disengagement, reduced adolescent autonomy granting, adolescent maladaptive emotion regulation, parental suppression of adolescent positivity and incongruent parent-child communication styles were relatively consistently related to youth depression. Nonetheless, there were conflicting findings and several studies demonstrated little or no contribution of parent-child interaction factors to youth depression. Overall, the evidence suggests that causal influences are likely to be modest. The majority of studies relate to maternal versus paternal interactions. Furthermore, the factors that mediate the association between parent-child interactions and youth depression remain largely unknown. Implications for future research and clinical practice are discussed.
\end{abstract}

Keywords: Parent-child interactions, observations, depression, childhood, adolescence 


\section{INTRODUCTION}

Major depression is the most common psychological problem for young people, with approximately $10 \%$ of children and adolescents meeting the criteria for a depressive disorder (Costello, Erkanli \& Angold, 2006). Experiencing a first episode of depression in early life is associated with many psychosocial difficulties in adulthood, such as unemployment, substance misuse, and other psychiatric disorders (Fergusson \& Woodward, 2002; Lewinsohn, Rohde, Seeley, Klein \& Gotlib, 2003). This makes depression an important target for clinical intervention in order to prevent pervasive and enduring negative outcomes later in life. Elucidating the specific mechanisms by which depression in young people is precipitated and maintained is also crucial to improving existing clinical interventions, which currently yield modest effect sizes (Weisz, McCarty \& Valeri, 2006).

Over the last decade there has been increased interest in the role of family interactions in the onset and maintenance of depression in childhood and adolescence (MacPhee \& Andrews, 2006; Restifo \& Bögels, 2009; Sander \& McCarty, 2005; Stice, Ragan \& Randall, 2004; Yap, Pilkington, Ryan \& Jorm, 2014). The importance of the parent-child relationship in the development of youth depression has been implicated in several theoretical models (e.g. Beck, 1967; Bowlby, 1980). For example, Beck's cognitive theory of depression assumes a major contribution of early life experiences to the development of depressogenic schemas (Beck, 1967). Despite the longstanding hypothesis that family factors play a large role in child psychological wellbeing, to date the relative contribution of parental factors to child and adolescent depression has found to be small and evidence is mixed. For example, one metaanalysis concluded that although parental factors are associated with childhood depression, the 
amount of variance explained was relatively low (McLeod, Weisz \& Wood, 2007). Similarly, a second meta-analysis found little or no association between parenting style (authoritarian, authoritative, permissive) and depression in childhood and adolescence (Yap, et al. 2014). However, many studies that contributed to meta-analytic reviews in the field utilised parent and child self-report measures of family functioning and relationships. This is problematic for several reasons. First, subjective reporting of the quality of parent-child relationships may be negatively biased due to presence of depressed mood in both parents and young people. Second, parent and child reports are known to differ and parents may give a more positive account of their parenting than their children, possibly due to social desirability (Sheeber, Hops \& Davis, 2001). Third, the reciprocal influences of parent and child behaviour are difficult to capture using self-report methods and it can be difficult to establish which parent-child interactive sequences predispose or maintain depressive affect and behaviour.

One way to overcome these potential problems is to use observational methodology for capturing parent-child interactive behaviour. Observational methods are seen as the gold standard in developmental behaviour research, as they can access temporal dynamics and nonverbal communications, providing richer accounts of family processes (Zeman, Klimes-Dougan, Cassano \& Adrian, 2007). Furthermore, a larger contribution of parental factors to youth depression has been demonstrated in observational studies compared with studies using selfreport methods (McLeod et al. 2007), suggesting that they are also more sensitive to detect the aspects of parent-child relationships that are relevant to depression. Several existing depression reviews have broadly covered or included family factors (McLeod et al. 2007; Restifo \& Bögels, 2009; Sander \& McCarty, 2005; Schwartz, Sheeber, Dudgeon \& Allen, 2012; Yap et al. 2014). By contrast, the aim of the current review is to provide a specific focus on how observed aspects 
of parent-child interactions are associated with the development and maintenance of depression, and the processes by which they may contribute to the disorder.

\section{METHOD}

\section{Data Sources}

A search of the literature was conducted between January 2013 and March 2015 and only peer-reviewed published studies were included. The search was initially conducted through electronic databases (PubMed, PsychInfo) to obtain key articles using search terms such as (parent* OR parent-child OR family OR mother-child relations OR parent-child relations) AND (depressi* OR dysthym* OR internalis*) AND (adolescent OR youth OR child) AND (interact* OR observ*). Relevant papers were selected and the reference lists of these articles, as well as other relevant reviews of the literature were screened to identify additional papers missed by the database search. Additional articles were retrieved by reviewing citation searches of key journal articles found on Google Scholar.

\section{Inclusion Criteria}

Studies were included in the analysis if they met the following criteria: a) observational methodology was used to measure interaction between children/adolescents and their parent(s); b) the sample included children and adolescents aged between 0 and 18 years old; c) child and/or adolescent depressive status or symptomology were measured as an outcome using standardised tools; and d) associations between parent-child interaction and child/adolescent depression were statistically examined. 


\section{RESULTS}

The search method yielded a total of 37 peer reviewed journal articles and these studies are summarised in Table 1. It was found that 18 studies used a between-subjects design to compare parent-child interactions of children or adolescents who met the criteria for major depression, with young people who had alternative psychiatric diagnoses (e.g. schizophrenia or conduct disorder) or healthy controls. The remaining 19 studies investigated the relationship between various aspects of parent-child interactions and self-reported, parent-reported or teacher-reported child or adolescent depressive symptoms. Of these correlational studies, it was found that 8 used a cross-sectional design and 11 used a longitudinal design.

\section{$<$ INSERT TABLE 1 HERE $>$}

The ages of participants ranged from 12 months to 18 years of age, but the majority of studies investigated depression in late childhood and across adolescence (between 8 and 18 years). The most commonly utilised method for assessing interactions was observing parents and children discussing topics of conflict or planning a positive event. Affective and behavioural displays were identified using objective coding schemes and analysed in terms of frequency and duration. We categorised and summarised studies according to whether they focused particularly on parental or child behaviour and the type of parenting behaviour observed, with some studies contributing to more than one section.

\section{Parental Behaviour}

Parental criticism and aggression. The role of aversive parental behaviour in the development and maintenance of youth depression has been the focus of several observational 
studies (Restifo \& Bögels, 2009). It is hypothesised that parental aggression and criticism may contribute to child depression by modelling negative interpersonal communication, evoking submissive responses and eliciting feelings of rejection in the young person (Eisenberg, Cumberland \& Spinrad, 1998; Keltner \& Kring, 1998). However, studies exploring the relationship between observed parental critical and aggressive behaviour during parent-child interactions and youth depression have found mixed results. In terms of research employing a correlational design, Yap and colleagues, in a study of 163 youth (starting age range 11-13 years) found that a higher frequency of parental aggressive and aversive behaviour (defined as being angry, disapproving and argumentative) during a positive event planning task predicted the amount of adolescent self-reported depressive symptoms both cross-sectionally (Yap, Schwartz, Byrne, Simmons \& Allen, 2010) and longitudinally. In follow-up assessments with the same sample two years later this effect was replicated, even when controlling for baseline depressive symptoms (Schwartz, Dudgeon, Sheeber, Simmons \& Allen, 2011; Schwartz, Dudgeon, Sheeber, Yap, Simmons \& Allen, 2012). This suggests that parental behaviour is not merely a response to ongoing youth depression.

In contrast, other studies have failed to find a direct association between parental critical or aversive behaviour during conflict resolution or problem-solving tasks and adolescent depressive symptoms either cross-sectionally (Corona, Lefkowitz, Sigman \& Romo, 2005; Tompson, Langer \& Davilla, 2012) or over time, after controlling for initial baseline depressive symptoms (Burge \& Hammen, 1991; Gaté, Watkins, Simmons, Byrne, Schwartz, Whittle, ... Allen, 2013; Sagrestano, Paikoff, Holmbeck \& Fendrich, 2003). One longitudinal study also demonstrated that higher maternal anger during a conflict task predicted fewer adolescent internalising symptoms two years later (Hofer, Eisenberg, Spinrad, Morris, Gershoff, Valiente ... 
\& Eggum, 2013), suggesting that maternal expression of negative emotion was adaptive for future wellbeing. Within study age ranges were relatively broad and varied substantially across samples, which may have made effects more difficult to detect. Nonetheless, samples were generally well powered, with the largest of these studies having an initial sample size of 275 adolescents (Sagrestano et al. 2003).

There has also been inconsistency in studies that examined differences in amount of parental aversive behaviour between depressed and non-depressed children and adolescents. For example, Sheeber and colleagues in their case-control study of 243 adolescents reported that those with clinical depression experienced a greater frequency of maternal aversive behaviour during a problem-solving task than those with sub-diagnostic symptoms or no symptoms (Sheeber, Davis, Leve, Hops \& Tildesley, 2007). Similarly, Dadds and colleagues found that mothers of depressed adolescents showed more aversive parenting behaviour than control group mothers during a naturalistic home interaction. Moreover, this aversive behaviour was seen to be directed to all siblings, suggesting it was a maternal trait (Dadds, Sanders, Morrisson \& Rebgetz, 1992). The same study did not find a between-group difference in paternal behaviour. However, the sample size was small and results should be treated cautiously. Other sudies have shown comparable amounts of parental aggressive and critical behaviour during problem-solving interactions for depressed children and adolescents and healthy controls (Hamilton, Asarnow \& Tompson, 1999; Sanders, Dadds, Johnston \& Cash, 1992), including one large scale study which included 86 depressed adolescents and 408 controls (Sheeber \& Sorensen, 1998). Finally, two studies have investigated the contribution of adolescent response to negative parental behaviour. It has been reported that female adolescents who responded to their mother's aversive behaviour with aggression during an observed problem-solving task reported more concurrent depressive 
symptoms, although this reciprocal effect was not observed for boys (Yap, Allen, O’Shea, Di Parsia, Simmons \& Sheeber, 2011; Yap et al. 2010). However, the cross-sectional method makes it difficult to ascertain whether presence of symptoms increased the level of aggressive responses.

In sum, there is considerable inconsistency in the evidence for the association between aggressive or critical parental behaviour and depression. Effects of aversive parental behaviour seemed to emerge more reliably during positive rather than negative tasks, possibly due to the fact that aversive behaviour during conflict resolution tasks may be expected, rather than representing a dysfunctional process. Discrepant findings between the studies may be explained by the fact that several different definitions of parental behaviour were used, including aggression, criticism and aversiveness, making it difficult to define exactly which aspects of the parental behaviour were most relevant. Nonetheless, the studies reviewed included some relatively large samples, and if effects of parental criticism were strong a more consistent pattern of findings in these larger studies would be expected. The limited longitudinal evidence demonstrating that parental behaviour predicts future depression is problematic, as aversive parental behaviour could represent a reaction to young people's depressive symptoms rather than a contributing or maintaining factor. Further investigations into the processes that may mediate the association between aversive parental behaviour and depression are required.

Parental reciprocity of anger. Parent-child conflict is typical during adolescence, as new roles and responsibilities are negotiated. However, high amounts of conflict during problem-solving tasks are likely to impair resolution of difficulties, limiting opportunities for the young person to learn negotiation skills (Gotlib \& Hammen, 1992). A study following the same 
participants in the aforementioned studies by Yap and others, also found that adolescent girls were at increased risk for depression around two and a half years later when their mothers reciprocated their angry affect during a positive event planning task (Schwartz et al. 2011), although they did not follow up whether adolescent responses to maternal aggression predicted depression over time. Furthermore, when the same participants were followed up six years later, they found that observed maternal reciprocation of adolescent aggressive behaviour during the event planning task was predictive of the onset of female depression (Schwartz, Byrne, Simmons, Whittle, Dudgeon, Yap ... Allen, 2014). However, the opposite effect was found for boys, as reduced maternal aggression in response to boys' aggression during the task was predictive of depression over the course of six years. In contrast, a separate case-comparison study comparing mother-adolescent interactions of depressed adolescents and healthy controls failed to find a between-group difference in the amount of mother's reciprocation of adolescent aggression over the course of a problem-solving interaction (Sheeber, Allen, Davis \& Sorensen, 2000).

These findings demonstrate emerging evidence that maternal reciprocation of anger increases the risk of female adolescent depression, possibly due to girls being more sensitive to the effects of maternal inability to modulate negative affect. However, there is no evidence to suggest that parent-child reciprocation of anger differs between clinical groups and healthy controls. At present, the body of work investigating this pattern is small and so further longitudinal studies and case-comparison studies are required.

Maternal disengagement. Disengagement during an interaction is characterised by a lack of affection, little emotional responsiveness and reduced attempted communication (Shaw, 
Schonberg, Sherrill, Huffman, Lukon, Obrosky \& Kovacs, 2006). Parental disengagement may signal to the young person that they are not valued by their parent and/or parent is unavailable for emotional support, possibly leading to negative beliefs about the self and others. There is some evidence to suggest that more maternal disengagement during parent-child conflict is associated with depression over time. Jacobvitz, Hazen, Curran and Hitchens (2004) investigated the role of maternal behaviour during a naturalistic observation, where mothers provided caregiving to their children aged 24 months $(n=108)$. Greater maternal disengagement, defined as being emotionally distant and not making room for feelings during the task, was associated with teacher-rated but not maternal-rated child depressive symptoms over five years later. Similarly, Burge and Hammen (1991) in their longitudinal study of 8-16 year olds $(\mathrm{n}=57)$ found that lower maternal task involvement observed during a problem-solving task was also associated with higher levels of adolescent depressive symptoms six months later, although this was not over and above baseline depressive symptoms. A third longitudinal study found that more maternal disengagement during an interaction task, defined as low support, responsiveness and communication, was significantly associated with female but not male child and adolescent (ages 9-20 years, $\mathrm{n}=406$ ) depressive symptoms four years later (Ge, Lorenz, Conger, Elder \& Simons, 1994). However, initial baseline symptoms were not controlled for.

Consistent with these correlational findings, evidence of a between-group difference for those with and without depression in amount of maternal disengagement has also been identified. Dietz and colleagues (2008), in a 21-year longitudinal programme of research, reported that mothers of children 8-17 years old who were depressed or were at high risk of depression (at least one first degree and at least one second degree relative with a history of depression) demonstrated more disengagement during a problem-solving task than mothers of control 
children. Furthermore, they found that mothers of depressed children continued to show high levels of task disengagement regardless of child remission status, suggesting that maternal disengagement was a stable characteristic of the parent-child relationship. Unfortunately, due to a small sample size, particularly for the high risk group $(n=28)$, they were unable to make any conclusions about whether disengagement predicted child depressive status.

In conclusion, these studies, some of which employed large sample sizes, show relatively consistent support for the association between maternal disengagement and depressive symptoms over time. However, as longitudinal studies did not typically control for baseline levels of depression, it remains possible that maternal disengagement is a reaction to young people's depression, may maintain depression after the onset of symptoms, or may not be causally related to depression. The observation that parental disengagement was a stable characteristic of the parent-child relationship which did not change after young people are in remission tends to suggest that it is not simply a response to child difficulties. Nonetheless, maternal disengagement may be attributed to potential confounding factors such as maternal mood or depressive status. Further studies accounting for these variables are required.

Parental dysphoria and low positivity. Low parental positivity and dysphoria directed towards young people during observed interactions have been studied in relation to adolescent depression. Expression of parental dysphoria may model a way of coping with difficult interpersonal interactions and serve to discourage young people's expressions of positivity within parent-child interactions (Yap, Allen \& Ladouceur, 2008). Negative parental responses to young people's positive affect during parent-child interactions is likely to reinforce the suppression of positive emotions in the parent-child dyad. Furthermore, recent studies have 
shown that low maternal warmth is associated with reduced adolescent response to reward (Morgan, Shaw \& Forbes, 2014), which is a clear risk factor for depression. A relatively small number studies were identified which examined the association between low parental positivity and adolescent depression, but findings were fairly consistent. Pineda and colleagues (Pineda, Cole \& Bruce, 2007) compared adolescents with and without high levels of depressive symptoms and found lower levels of parental positivity during a conflict resolution task to be associated with adolescent depressive symptomology. Messer and Gross (1995) looked at interactions between parents and their children, where half had high depressive symptomology and half had low depressive symptomology. Parents of children with high depressive symptoms were shown to reciprocate child positive emotion at comparable rates to parents of children with few symptoms, but the frequency of overall positive parental behaviour was less for parents of children with depressive symptoms. The sample size in this study was very small $(\mathrm{n}=20)$ so findings should be interpreted with caution. In another study, low levels of maternal positivity were found to be prospectively associated with increased youth internalising symptoms one year later, although baseline adolescent symptoms were not assessed (Hofer et al. 2013).

The concept of dysphoria may differ from that of low positivity, as it is measured based on active behaviour, such as whining and complaints, rather than an absence of positive behaviour. One study exploring the mother-child interactions of young adolescents found that maternal dysphoria in response to adolescent positive affect during event planning and problemsolving tasks was associated with more concurrent adolescent depressive symptoms (Yap et al. 2008). However, two studies have failed to show a relationship between parental responses to child positivity and depression. Firstly, a study that observed parent-child interactions with both children and adolescents did not find a significant association between the amount of parental 
reciprocal positivity during problem-solving tasks and child or adolescent depression (Jacob \& Johnson, 2001). Schwartz and colleagues (2012) also did not find any association between parental dysphoria, which included self-derogatory comments, during positive event planning task and problem-solving tasks, and the onset of adolescent depressive symptomology over two years later. However, when these participants were followed up over the course of 6 years, they found that adolescents whose mothers responded to their positive behaviour with dysphoria during problem-solving-tasks were at increased risk of the onset of depression over time (Schwartz et al. 2014). This study also controlled for symptoms of maternal depression, but did not measure baseline adolescent depressive symptoms. These findings suggest that the discouragement of adolescent positivity in parent-child interactions may reinforce behavioural displays of depression.

These findings show some evidence for the role of low levels of parental positivity and dysphoria as a contributing factor to adolescent depression. The limited evidence indicating a relationship between these particular parental responses to child positivity and child depression suggests that parents of depressed children do reciprocate positive affect but on a less frequent basis than parents of children with few symptoms, which may mean that the frequency of opportunities for positive reinforcement may be reduced for young people with depression. There is also some evidence to suggest that negative parental responses to child positivity may be associated with an increased risk of depression over time, accounting for maternal depressive symptoms. Further studies exploring whether repeated suppression of positivity decreases a young person's ability to process reward would also be useful to highlight potential mediators linking positivity suppression and adolescent depression. Again, the absence of longitudinal studies assessing and controlling for baseline symptoms or parental mental health limits the 
conclusions that can be drawn about the causality of the relationship between parental behaviour and depression, and it is possible that low positivity is a result rather than a cause of youth depression.

\section{Positive Parental Responses to Depressive Behaviour}

The development of depression throughout childhood and adolescence is likely to alter family interactions and may be reinforced by the reaction of others. One theory proposes that adolescent dysphoria can be functional within a conflictual family environment by suppressing parental negativity and criticism (Eisenberg et al. 1998). Also, adult interpersonal theories of depression hypothesise that depression initially elicits care-giving behaviour from others but this reduces over time (Coyne, 1976; Hames, Hagan \& Joiner, 2013). Sheeber and colleagues found that fathers, but not mothers of clinically depressed adolescents were more likely to decrease aggressive behaviour in response to adolescent depressive behaviour during a problem-solving interaction than fathers of non-depressed adolescents (Sheeber, Hops, Andrews, Alpert \& Davis, 1998). Interestingly, this study also found that depressive status over time was not related with parental responses to adolescent behaviour, suggesting that parent-child interactions were a stable factor and not a response to youth depression. Another study also found that rates of maternal smiling were shown to increase as the child self-reported depressive symptoms increased (Dadds et al. 1992). Interestingly, in a non-depressed sample of adolescents, when adolescent depressive behaviour decreased, parental aversive behaviour also decreased (Slesnick \& Waldron, 1997) 
These studies suggest that adolescent displays of dysphoria tend to elicit more positive parenting behaviour and/or may suppress negative parental behaviour, thus negatively reinforcing depressive behaviour. However, in the absence of longitudinal evidence it is not clear whether this parental response is adaptive or unhelpful. It is notable that alongside the evidence that parents naturally reduce negative behaviours in response to adolescent dysphoric behaviours, two studies suggest that this may happen less for the parents of clinically depressed young people. Again, whether this is a process relevant to the development and maintenance of depression or a reaction to more frequent child displays cannot be established from the crosssectional findings.

\section{Parent-Child Communication Styles}

Attuned or sensitive parent-child communication refers to a parent's ability to recognise and respond appropriately to their child's emotional experience and a lack of attunement can result in poorer coping abilities and intolerance of negative affect (Fonagy, Steele, Steele, Moran \& Higgitt, 1991). One study examined the verbal and behavioural communication styles of parents of depressed adolescents compared with healthy controls (Slesnick \& Waldron, 1997). Results showed that parents of depressed adolescents were more likely to pair verbal aversive content with positive affect behaviours during observed parent-child conflict task than parents of non-depressed adolescents, demonstrating a 'mixed-messages' style of communication. This incongruent communication may be confusing for the young person and may represent attempts to conceal negative feelings towards their child, possibly due to social desirability effects. Another study also found that mothers of depressed children were less contingently responsive to their children during free-play and puzzle completion tasks, compared with mothers of non- 
depressed children (Field, Sandberg, Goldstein, Garcia, Vega-Lahr, Porter \& Dowling, 1987). In addition, a recent study looked at affective matching between parents and adolescents during a problem solving task (Hollenstein, Allen \& Sheeber, 2015). They found that clinically depressed adolescents were quicker to return to discrepant affective states and slower to return to matched affective states with their parents than healthy controls, suggesting some difficulties achieving emotional attunement.

In summary, the limited existing research shows some evidence that parent-child communication may be incongruent and mismatched and that discrepancies exist between parent-child affective states for depressed adolescents, compared with those without depression. However, due to the absence of longitudinal studies, it is unclear as to whether this communication style was present prior to the onset of depression or whether it emerged as a result of depression onset.

\section{Child and Adolescent Behaviour}

Emotional regulation. The process of emotional regulation, which involves "initiating, maintaining, and modulating the occurrence, intensity, and expression of emotions" (Morris, Silk, Steinberg, Myers \& Robinson, 2007), is likely to be an important factor in how adolescents respond to interactions with their parents, particularly in the context of conflict. Emotional dysregulation during interpersonal difficulties can lead to the development of ineffective conflict resolution strategies, which are associated with internalising difficulties (Eisenberg, Spinrad \& Eggum, 2010; Nolen-Hoeksema, Parker \& Larson, 1994). The suppression of emotional expression is a core regulatory strategy in models of emotion regulation, and is held to be maladaptive. 
Low levels of observed negative affect during conflict have been shown to differentiate depressed individuals from controls. Dadds et al. (1992) found that lower levels of aversive behaviour of children and young adolescents (7-14 years old) with mixed depression and conduct difficulties $(n=12)$ during an observed family meal was associated with higher adolescent reported depressive symptoms concurrently. However, this effect was not found for adolescents with depression only $(n=12)$. In addition, a second study using the same sample found that depressed young people showed relatively low levels of anger during a problem-solving task with their parents compared to controls (Sanders et al. 1992). This may suggest either the increased use of emotional suppression during conflict or a genuine absence of negative affect. However, the small sample size means that these observations should be treated cautiously.

In contrast to these findings, several well-powered studies have found that depressed adolescents express more negative affect during parent-child interactions. For example, when compared with healthy controls, depressed adolescents have been shown to demonstrate increases in dysphoria across the course of a parent-child conflict task (Sheeber, Kuppens, Shortt, Katz, Davis \& Allen, 2012), as well as maintaining depressive and aggressive behaviours for longer durations (Sheeber et al. 2000) and showing longer durations and higher frequencies of anger and dysphoria during conflict (Sheeber, Allen, Leve, Davis, Shortt \& Katz, 2009). In addition, Kuppens and colleagues have focussed on the inflexible use of emotional regulation strategies by measuring the amount of 'emotional inertia' during parent-child interactions, defined as the presence of a stable emotional state that does not change readily (Kuppens, Sheeber, Yap, Whittle, Simmons \& Allen, 2012). The first case-comparison study found that depressed adolescents showed a greater degree of emotional inertia for positive and negative behavioural displays over the course of parent-child conflict, compared with healthy controls 
(Kuppens, Allen \& Sheeber, 2010). A further longitudinal study $(n=165)$ found that high adolescent emotional inertia was predictive of the first episode of clinical depression two and a half years later in an independent sample of non-depressed adolescents (Kuppens, Sheeber, Yap, Whittle, Simmons \& Allen, 2012). This result still remained when controlling for parent behaviour, age, gender and number of depressive symptoms, which may show that an inability to modulate affect in response to the interpersonal context is a risk factor for the development of depression. Together these studies suggest that showing more emotion or the inflexible use of emotion regulation in interactions with parents, possibly due to fewer adaptive emotional management strategies, is associated with depression.

One explanation for the discrepancy in findings on the association between the degree of emotional expression and depression, is that young people may be able to express their emotions more readily in low conflict, rather than high conflict environments. Jackson, Kuppens, Sheeber and Allen (2011), found that depressed adolescents whose families displayed low parental anger exhibited a greater degree of angry behaviour during parent-child conflict than non-depressed adolescents. However, there were no differences in anger expression for depressed adolescents compared to healthy controls from a high anger family. Therefore, depressed adolescents from families characterised by high anger and conflict may not feel they can express their negative emotions and avoid escalating negative affect by suppressing feelings. However, none of the reported studies looking at child and adolescent expressions of affect across the interactions assessed whether reductions in reported negative affect represented greater efforts to control negative emotions or whether young people did not experience conflict with their parents as distressing. 
Only one study has explicitly measured adolescents' use of maladaptive emotional regulation strategies during parent-child conflict. Adolescents' use of maladaptive emotion regulation strategies, such as engaging in conflict to solve interpersonal problems and mirroring parental dysphoria, mediated the association between the frequency of aversive maternal behaviour during a positive parent-child task and depressive symptoms concurrently (Yap et al. 2010). It is possible that negative parental behaviour may increase adolescent negative affect, in turn activating maladaptive emotional regulation strategies to manage these feelings.

Collectively, these studies show evidence for the use of both low and high emotional expression during parent-child interactions in young people with depression, compared with healthy controls. This could mean that maladaptive emotional responding may be a maintaining factor or response to depressive symptoms. Also, one study demonstrated emotional inertia as a predictive factor for the onset of depression, suggesting that low levels of emotional flexibility during parent-child conflict could be indicative of a predisposing factor for depression. However, only two studies included the use of specific emotional regulation strategies as mediator variables meaning that further studies examining the underlying processes are required. It is also unclear whether the emotional regulation abilities of young people with depression are likely to be reduced due to low mood or whether maladaptive coping strategies were a pre-morbid characteristic for those with depression.

Reduced autonomy. Establishing autonomy and independence, whilst maintaining closeness with parents is one of the central tasks of adolescence (Eisenberg et al. 1998). Young people who are not granted an appropriate amount of autonomy in relation to decision-making may be vulnerable to depression, due to assuming a passive role in relationships where their own 
wishes and opinions are not expressed (Hare, Szwedo, Schad \& Allen, 2014). It has been found that a lower amount of autonomy during parent-child interactions, such as low levels of adolescent independence and responsibility, predicted higher adolescent rated concurrent depressive symptoms (Lewandowski \& Palermo, 2009). It has also been found that low levels of adolescent assertiveness, which represents one aspect of autonomy, during a problem-solving task with their parents were found to be associated with increased concurrent depressive symptomology (Kobak, Cole, Ferenz-Gillies, Fleming \& Gamble, 1993). Furthermore, adolescent "autonomy undermining" behaviour during problem-solving interactions with their mother, such as over-personalising a disagreement or recanting an opinion, was found to predict increases in depressive symptomology one year later, even when controlling for baseline symptoms of depression (Allen, Insabell, Porter, Smith, Land \& Phillips, 2006). However, differences in the amount of observed adolescent autonomy during a parent-child problemsolving interaction when comparing depressed adolescents with those with externalising difficulties and healthy controls have not been identified (Pavlidis \& McCauley, 2001).

Overall, research has shown some consistency in linking a lack of autonomous behaviour and depressive symptoms, yet it has looked at a relatively disparate set of constructs and this is a small body of work. Only one longitudinal study has been conducted, which limits the conclusions that can be drawn about the predisposing and maintaining role of reduced autonomy in depression. More work needs to be done to both define this construct and determine its significance and as most studies focused on adolescent behaviour rather than the dynamics, is it unclear whether the adolescent is responding to parental behaviour, initiating behaviour, or both. 
Parent-child role confusion. The concept of enmeshment and role confusion has also been explored in relation to youth depression, which may include spousification, where parents rely on children for intimacy and companionship (Sroufe, Jacobvitz, Mangelsdorf, DeAngelo \& Ward, 1985) or parentification, where the child is encouraged to fulfil a parental role by taking on responsibility (Byng-Hall, 2008). Jacobvitz et al. (2004) found that more 'enmeshed' relationships, which included parents relying on their children for guidance at 24 months were associated with higher levels of teacher-rated, but not mother-rated depressive symptoms at age seven years for girls only. This suggests that girls may be particularly vulnerable to parental attempts to give them inappropriate levels of responsibility. Nevertheless, it was not clear from the study whether the overall amount of this role reversal was higher for girls than boys; it may have been the case that girls were more affected because it occurred more frequently. A longitudinal study also found that children who engaged in observed interactions where parents and children acted in a 'peer-like' manner were more likely to report concurrent symptoms of depression, yet this type of interaction was not predictive of symptoms over time when controlling for baseline symptoms and parental depression (Sagrestano et al. 2003).

\section{DISCUSSION}

This review summarised the evidence investigating the association between observed aspects of parent-child relationships with the onset and maintenance of depression in childhood and adolescence. Although there was much inconsistency in the findings, several aspects of the parent-child interaction emerged as providing relatively consistent evidence in the association with depression. Within the domain of parental factors, it was found that there was more reliable evidence for the effect of low levels of parental positivity on depressive symptoms, which may 
suggest that an absence of positive reinforcement is more detrimental to child and adolescent wellbeing than active aversive behaviour. In terms of attachment and development of internal working models, young people may come to believe that parents are unavailable for emotional support and the absence of positive interactions may communicate to young people that they are "unlikeable." These beliefs may be central to the development of low self-worth and subsequent depression. The findings on aversive parental behaviour were largely mixed and although the studies investigating maternal disengagement were more consistent, there was a lack of prospective research, limiting the causal inferences that can be made (Branje, Hale, Frijns \& Meeus, 2010).

The evidence looking at child and adolescent behaviour during the parent-child interaction and the association with depression found generally clearer evidence for the role of reduced adolescent autonomy. Negotiating appropriate amounts of autonomy across adolescence has been highlighted as a task where difficulties may arise (Hare et al. 2014); adolescents who are not encouraged to develop an identity away from the family may be vulnerable to depression. The literature on child and adolescent emotional regulation during parent-child interactions also broadly supported the assumption that interpersonal emotion regulatory difficulties are likely to typify depressed adolescents. However, the specific nature of the disturbance identified varied significantly, with evidence for emotional inhibition, inflexibility and under-control each being linked to depression. This variability could be explained by the family context, developmental stage of the child, or whether parents are likely to reinforce emotional expression or not (Schwartz, Sheeber, Dudgeon \& Allan, 2012). Future studies using mixed methods approaches 
using both observations of emotional displays and youth self-report of underlying emotions are likely to be helpful to understand the complex processes that occur across parent-child interactions.

Studies investigating parent-child interactive behaviour across the course of the interaction also demonstrated mixed results. Maternal reciprocation of adolescent anger was found to be particularly detrimental for females, while males were more affected by low levels of maternal reciprocation of anger. It is possible that females are more sensitive to mother-child conflict, or that females at high risk of depression experience more conflict (Schwartz et al. 2014). Furthermore, although the evidence on the association between positive parental responses to young people's dysphoria was mixed, some studies did find that expressions of adolescent dysphoria were shown to increase positive parental behaviour or decrease parental aggression. This could mean that dysphoria becomes a reinforced behaviour designed to moderate negative parental behaviour in the absence of adaptive conflict resolution strategies, although further evidence is needed to reliably establish this association. In addition, there was some evidence to suggest that incongruent parent-child communication and affect was related to depression, although it is currently unknown as to whether this aspect of the relationship has any predictive relationship with depression.

Several of the identified interaction patterns may be linked to a reduced ability, in the context of depression, to clearly understand others' (and own) internal states. The work on mentalization may be very relevant when interpreting these difficulties in parent-child interactions (Allen, Fonagy \& Bateman, 2008). Although no studies to date have specifically examined the relationship between mentalization and youth depression, there is reason to believe 
that depression in youth may be associated with reduced capacity for mentalization, which may influence the ability for youth to communicate and interact effectively with their parents.

We expect that highlighting the parent-child factors that are associated with depression will be useful for designing clinical interventions, especially as the translation of research findings into effective clinical interventions for young people with depression is currently limited. It is likely that family environments that maintain depression affect response to treatment, potentially diminishing the beneficial effects of individual evidence-based treatments (Kolko, Brent, Baugher, Bridge \& Birmaher, 2000). Observational research could be translated into clinical intervention through in vivo application with families to identify and change the types of interactions that are known to be related to depression, or the development of associated interviews and questionnaires that tap into dimensions that are relevant to this problem. Although this is a common method for infant attachment interventions, it is likely that the benefits could extend to older age groups.

The review identified several methodological limitations of the extant research. Firstly, the research has largely neglected the role of father-child relationship, which may be important for either buffering or exacerbating particular negative mother-child relationships and further studies should investigate the relative contribution of the relationship with each parent. There are also a number of child characteristics that need to be considered further in observational studies, such as child temperament, personality traits, history of depression and neurological/biological factors, which may be influential in parent-child interactions. It is recognised that depression involves a complex range of risk factors and there may be a number of pathways of interacting 
factors in the development and maintenance of depression (Garber, 2005). Further work may clarify the extent of the child's contribution to family interactions in the context of depression.

Although this review only included studies using observational methodology, it is clear that there is much variety in the type of task, the affective and behavioural coding systems, participant age, the measurement of depression and the conceptualisation of different parentchild interaction characteristics. Many studies used self-reported measures of internalising symptoms and although these do include depressive symptoms, it would be more rigorous to use diagnostic interviews to determine depressive status. Finally, few studies controlled for comorbid difficulties such as anxiety disorders or behavioural problems, meaning that the specificity of the parental behaviours described above for contributing solely to depression over other emotional difficulties needs to be established.

\section{Conclusion and Future Directions}

The review highlighted that further evidence is needed to clarify the specific mechanisms by which youth depression may develop and be maintained by interactions with their parents, and to identify how to intervene. More focus is also needed on how child characteristics may influence these interactions. Also, as adolescence marks a shift between reliance on parents to peers, studies could investigate how child-peer interactions contribute to depression, but also explore the protective effects of positive relationships with others on negative parent-child relationships and vice versa. The ability of future research to specifically determine which aspects of parent-child relationships predispose and perpetuate depression in childhood and adolescence is likely to be crucial for improving existing clinical interventions to produce better outcomes for future wellbeing of youth and to more effectively support parents and families. 


\section{ABOUT THE AUTHORS}

Dr Rosanna Chapman is a registered Clinical Psychologist working in a Child and Adolescent Mental Health Service in North Somerset, UK. She completed her doctorate in Clinical Psychology at the University of Bath.

Dr Monika Parkinson is a National Institute of Health Research (NIHR) Doctoral Research Fellow at the University of Reading and a registered Clinical Psychologist.

Dr Sarah Halligan is a Reader (Associate Professor equivalent) in Clinical Psychology at the University of Bath.

DISCLOSURE OF CONFLICT OF INTEREST: The authors declare that they have no biomedical or financial conflicts of interest relevant to this work.

\section{ACKNOWLEDGEMENTS}

This review was conducted in part in fulfilment of the first author's doctorate in clinical psychology whilst studying at University of Bath.

\section{REFERENCES}

Allen, J. G., Fonagy, P. \& Bateman, A. W. (2008). Mentalizing in Clinical Practice. Washington: APPI. 
Allen, J. P., Insabella, G., Porter, M. R., Smith, F. D., Land, D. \& Phillips, N. (2006). A socialinteractional model of the development of depressive symptoms in adolescence. Journal of Consulting and Clinical Psychology, 74(1), 55-65.

Beck, A. T. (1967). Depression: Clinical, experimental, and theoretical aspects. New York: University of Pennsylvania Press.

Bowlby, J. (1980). Attachment and Loss (Vol. 3). New York: Basic Books.

Branje, S. J., Hale, W. W., Frijns, T. \& Meeus, W. H. (2010). Longitudinal associations between perceived parent-child relationship quality and depressive symptoms in adolescence. Journal of Abnormal Child Psychology, 38(6), 751-763.

Burge, D. \& Hammen, C. (1991). Maternal communication: predictors of outcome at follow-up in a sample of children at high and low risk for depression. Journal of Abnormal Psychology, 100(2), 174-180.

Byng-Hall, J. (2008). The significance of children fulfilling parental roles: Implications for family therapy. Journal of Family Therapy, 30(2), 147-162.

Corona, R., Lefkowitz, E. S., Sigman, M. \& Romo, L. F. (2005). Latino adolescents' adjustment, maternal depressive symptoms, and the mother-adolescent relationship. Family Relations, 54(3), 386-399.

Costello, E., Erkanli, A. \& Angold, A. (2006). Is there an epidemic of child or adolescent depression? Journal of Child Psychology and Psychiatry, 47(12), 1263-1271. 
Coyne, J. C. (1976). Toward an interactional description of depression. Psychiatry, 39(1), 28-40.

Dadds, M. R., Sanders, M. R., Morrison, M. \& Rebgetz, M. (1992). Childhood depression and conduct disorder: II. An analysis of family interaction patterns in the home. Journal of Abnormal Psychology, 101(3), 505-513.

Dietz, L. J., Birmaher, B., Williamson, D. E., Silk, J. S., Dahl, R. E., Axelson, D. A., . . Ryan, N. D. (2008). Mother-child interactions in depressed children and children at high risk and low risk for future depression. Journal of the American Academy of Child \& Adolescent Psychiatry, 47(5), 574-582.

Eisenberg, N., Cumberland, A. \& Spinrad, T. L. (1998). Parental socialization of emotion. Psychological Inquiry, 9(4), 241-273.

Eisenberg, N., Spinrad, T. L. \& Eggum, N. D. (2010). Emotion-related self-regulation and its relation to children's maladjustment. Annual Review of Clinical Psychology, 6, 495-525.

Fergusson, D. M. \& Woodward, L. J. (2002). Mental health, educational, and social role outcomes of adolescents with depression. Archives of General Psychiatry, 59(3), 225231.

Field, T. M., Sandberg, D., Goldstein, S., Garcia, R., Vega-Lahr, N., Porter, K. \& Dowling, M. (1987). Play interactions and interviews of depressed and conduct disorder children and their mothers. Child Psychiatry and Human Development, 17(4), 213-234. 
Fonagy, P., Steele, M., Steele, H., Moran, G. S. \& Higgitt, A. C. (1991). The capacity for understanding mental states: The reflective self in parent and child and its significance for security of attachment. Infant Mental Health Journal, 12, 201-218.

Garber, J. (2005). Depression and the family. In J. L. Hudson \& R. M. Rapee (Eds.), Psychopathology and the Family (pp. 227-283). Oxford: Elsevier.

Gaté, M. A., Watkins, E. R., Simmons, J. G., Byrne, M. L., Schwartz, O. S., Whittle, S., ... Allen, N. B. (2013). Maternal parenting behaviors and adolescent depression: The mediating role of rumination. Journal of Clinical Child \& Adolescent Psychology, 42(3), $348-357$.

Ge, X., Lorenz, F. O., Conger, R. D., Elder, G. H. \& Simons, R. L. (1994). Trajectories of stressful life events and depressive symptoms during adolescence. Developmental Psychology, 30(4), 467-483.

Gotlib, I. H. \& Hammen, C. L. (1992). Psychological Aspects of Depression: Toward a cognitive-interpersonal integration. London: John Wiley \& Sons.

Hames, J. L. Hagan, C. R., \& Joiner, T. E. (2013). Interpersonal processes in depression. Annual Review Of Clinical Psychology, 9, 355-377.

Hamilton, E., Asarnow, J. \& Tompson, M. (1999). Family interaction styles of children with depressive disorders, schizophrenia-spectrum disorders, and normal controls. Family Process, 38(4), 463-476. 
Hare, A. L., Szwedo, D. E., Schad, M. M. \& Allen, J. P. (2014). Undermining adolescent autonomy with parents and peers: The enduring implications of psychologically controlling parenting. Journal of Research on Adolescence, 25(4), 739-752.

Hofer, C., Eisenberg, N., Spinrad, T. L., Morris, A. S., Gershoff, E., Valiente, C., ... Eggum, N. D. (2013). Mother-adolescent conflict: Stability, change, and relations with externalizing and internalizing behavior problems. Social Development, 22(2), 259-279.

Hollenstein, T., Allen, N. \& Sheeber, L. (2015). Affective patterns in triadic family interactions: Associations with adolescent depression. Development and Psychopathology.

Jackson, J., Kuppens, P., Sheeber, L. B. \& Allen, N. B. (2011). Expression of anger in depressed adolescents: The role of the family environment. Journal of Abnormal Child Psychology, $39(3), 463-474$.

Jacob, T. \& Johnson, S. L. (2001). Sequential interactions in the parent-child communications of depressed fathers and depressed mothers. Journal of Family Psychology, 15(1), 38-52.

Jacobvitz, D., Hazen, N., Curran, M. \& Hitchens, K. (2004). Observations of early triadic family interactions: Boundary disturbances in the family predict symptoms of depression, anxiety, and attention-deficit/hyperactivity disorder in middle childhood. Development and Psychopathology, 16(03), 577-592.

Keltner, D. \& Kring, A. M. (1998). Emotion, social function, and psychopathology. Review of General Psychology, 2(3), 320-342. 
Kobak, R. R., Cole, H. E., Ferenz-Gillies, R., Fleming, W. S. \& Gamble, W. (1993). Attachment and emotion regulation during mother-teen problem solving: A control theory analysis. Child Development, 64(1), 231-245.

Kolko, D. J., Brent, D. A., Baugher, M., Bridge, J. \& Birmaher, B. (2000). Cognitive and family therapies for adolescent depression: Treatment specificity, mediation, and moderation. Journal of Consulting and Clinical Psychology, 68(4), 603-614.

Kuppens, P., Sheeber, L. B., Yap, M. B., Whittle, S., Simmons, J. G. \& Allen, N. B. (2012). Emotional inertia prospectively predicts the onset of depressive disorder in adolescence. Emotion, 12(2), 283-289.

Kuppens, P., Allen, N. B. \& Sheeber, L. B. (2010). Emotional inertia and psychological maladjustment. Psychological Science, 21(7), 984-991.

Lewandowski, A. S. \& Palermo, T. M. (2009). Parent-teen interactions as predictors of depressive symptoms in adolescents with headache. Journal of Clinical Psychology in Medical Settings, 16(4), 331-338.

Lewinsohn, P. M., Rohde, P., Seeley, J. R., Klein, D. N. \& Gotlib, I. H. (2003). Psychosocial functioning of young adults who have experienced and recovered from major depressive disorder during adolescence. Journal of Abnormal Psychology, 112(3), 353-363.

MacPhee, A. R. \& Andrews, J. J. (2006). Risk factors for depression in early adolescence. Adolescence, 41(163), 435-466. 
McLeod, B. D., Weisz, J. R. \& Wood, J. J. (2007). Examining the association between parenting and childhood depression: A meta-analysis. Clinical Psychology Review, 27(8), 9861003.

Messer, S. C. \& Gross, A. M. (1995). Childhood depression and family interaction: A naturalistic observation study. Journal of Clinical Child Psychology, 24(1), 77-88.

Morgan, J. K., Shaw, D. S. \& Forbes, E. E. (2014). Maternal depression and warmth during childhood predict age 20 neural response to reward. Journal of the American Academy of Child \& Adolescent Psychiatry, 53(1), 108-117.

Morris, A. S., Silk, J. S., Steinberg, L., Myers, S. S. \& Robinson, L. R. (2007). The role of the family context in the development of emotion regulation. Social development, 16(2), 361388.

Nolen-Hoeksema, S., Parker, L. E. \& Larson, J. (1994). Ruminative coping with depressed mood following loss. Journal of Personality and Social Psychology, 67(1), 92-104.

Pavlidis, K. \& McCauley, E. (2001). Autonomy and relatedness in family interactions with depressed adolescents. Journal of Abnormal Child Psychology, 29(1), 11-21.

Pineda, A. Q., Cole, D. A. \& Bruce, A. E. (2007). Mother-adolescent interactions and adolescent depressive symptoms: A sequential analysis. Journal of Social and Personal Relationships, 24(1), 5-19.

Restifo, K. \& Bögels, S. (2009). Family processes in the development of youth depression: Translating the evidence to treatment. Clinical Psychology Review, 29(4), 294-316. 
Sagrestano, L. M., Paikoff, R. L., Holmbeck, G. N. \& Fendrich, M. (2003). A longitudinal examination of familial risk factors for depression among inner-city African American adolescents. Journal of Family Psychology, 17(1), 108-120.

Sander, J. B. \& McCarty, C. A. (2005). Youth depression in the family context: Familial risk factors and models of treatment. Clinical Child and Family Psychology Review, 8(3), 203-219.

Sanders, M. R., Dadds, M. R., Johnston, B. M. \& Cash, R. (1992). Childhood depression and conduct disorder: I. Behavioral, affective, and cognitive aspects of family problemsolving interactions. Journal of Abnormal Psychology, 101(3), 495-504.

Schwartz, O. S., Byrne, M. L., Simmons, J. G., Whittle, S., Dudgeon, P., Yap, M. B., . . Allen, N. B. (2014). Parenting during early adolescence and adolescent-onset major depression A 6-year prospective longitudinal study. Clinical Psychological Science, 2(3), 272-286.

Schwartz, O. S., Dudgeon, P., Sheeber, L. B., Yap, M. B., Simmons, J. G. \& Allen, N. B. (2011). Observed maternal responses to adolescent behaviour predict the onset of major depression. Behaviour Research and Therapy, 49(5), 331-338.

Schwartz, O. S., Dudgeon, P., Sheeber, L. B., Yap, M. B., Simmons, J. G. \& Allen, N. B. (2012). Parental behaviors during family interactions predict changes in depression and anxiety symptoms during adolescence. Journal of Abnormal Child Psychology, 40(1), 59-71. 
Schwartz, O. S., Sheeber, L. B., Dudgeon, P. \& Allen, N. B. (2012). Emotion socialization within the family environment and adolescent depression. Clinical Psychology Review, $32(6), 447-453$.

Shaw, D. S., Schonberg, M., Sherrill, J., Huffman, D., Lukon, J., Obrosky, D. \& Kovacs, M. (2006). Responsivity to offspring's expression of emotion among childhood-onset depressed mothers. Journal of Clinical Child and Adolescent Psychology, 35(4), 490-503.

Sheeber, L., Allen, N., Davis, B. \& Sorensen, E. (2000). Regulation of negative affect during mother-child problem-solving interactions: Adolescent depressive status and family processes. Journal of Abnormal Child Psychology, 28(5), 467-479.

Sheeber, L., Hops, H., Andrews, J., Alpert, T. \& Davis, B. (1998). Interactional processes in families with depressed and non-depressed adolescents: Reinforcement of depressive behavior. Behaviour Research and Therapy, 36(4), 417-427.

Sheeber, L., Hops, H. \& Davis, B. (2001). Family processes in adolescent depression. Clinical Child and Family Psychology Review, 4(1), 19-35.

Sheeber, L. \& Sorensen, E. (1998). Family relationships of depressed adolescents: A multimethod assessment. Journal of Clinical Child Psychology, 27(3), 268-277.

Sheeber, L. B., Allen, N. B., Leve, C., Davis, B., Shortt, J. W. \& Katz, L. F. (2009). Dynamics of affective experience and behavior in depressed adolescents. Journal of Child Psychology and Psychiatry, 50(11), 1419-1427. 
Sheeber, L. B., Davis, B., Leve, C., Hops, H. \& Tildesley, E. (2007). Adolescents' relationships with their mothers and fathers: associations with depressive disorder and subdiagnostic symptomatology. Journal of Abnormal Psychology, 116(1), 144-154.

Sheeber, L. B., Kuppens, P., Shortt, J. W., Katz, L. F., Davis, B. \& Allen, N. B. (2012). Depression is associated with the escalation of adolescents' dysphoric behavior during interactions with parents. Emotion, 12(5), 913-918.

Slesnick, N. \& Waldron, H. B. (1997). Interpersonal problem-solving interactions of depressed adolescents and their parents. Journal of Family Psychology, 11(2), 234-245.

Sroufe, L. A., Jacobvitz, D., Mangelsdorf, S., DeAngelo, E. \& Ward, M. J. (1985). Generational boundary dissolution between mothers and their preschool children: A relationship systems approach. Child Development, 317-325.

Stice, E., Ragan, J. \& Randall, P. (2004). Prospective relations between social support and depression: Differential direction of effects for parent and peer support? Journal of Abnormal Psychology, 113(1), 155-159.

Tompson, M. C., Langer, D. A. \& Davila, J. (2012). Maternal behavior and cognitive vulnerability in early adolescence. International Journal of Cognitive Therapy, 5(3), 268282.

Weisz, J. R., McCarty, C. A. \& Valeri, S. M. (2006). Effects of psychotherapy for depression in children and adolescents: a meta-analysis. Psychological Bulletin, 132(1), 132-149. 
Yap, M. B., Allen, N. B. \& Ladouceur, C. D. (2008). Maternal socialization of positive affect: The impact of invalidation on adolescent emotion regulation and depressive symptomatology. Child Development, 79(5), 1415-1431.

Yap, M. B., Allen, N. B., O'Shea, M., Di Parsia, P., Simmons, J. G. \& Sheeber, L. (2011). Early adolescents' temperament, emotion regulation during mother-child interactions, and depressive symptomatology. Development and Psychopathology, 23(01), 267-282.

Yap, M. B., Schwartz, O. S., Byrne, M. L., Simmons, J. G. \& Allen, N. B. (2010). Maternal positive and negative interaction behaviors and early adolescents' depressive symptoms: Adolescent emotion regulation as a mediator. Journal of Research on Adolescence, 20(4), 1014-1043.

Yap, M. B. H., Pilkington, P. D., Ryan, S. M. \& Jorm, A. F. (2014). Parental factors associated with depression and anxiety in young people: A systematic review and meta-analysis. Journal of Affective Disorders, 156, 8-23.

Zeman, J., Klimes-Dougan, B., Cassano, M. \& Adrian, M. (2007). Measurement issues in emotion research with children and adolescents. Clinical Psychology: Science and Practice, 14(4), 377-401. 
Table 1

Summary of Observational Parent-Child Interaction Studies.

\begin{tabular}{|c|c|c|c|c|c|c|}
\hline Study & $N^{*}$ & & Design & $\begin{array}{l}\text { Observational tasks and } \\
\text { coding system }\end{array}$ & Parent/child variables of interest & $\begin{array}{l}\text { Youth } \\
\text { depression }\end{array}$ \\
\hline Allen et al. (2006) & 143 & $13-14$ & $\begin{array}{l}\text { Longitudinal: } \mathrm{T} 1 \text { and } \mathrm{T} 21 \text { year } \\
\text { apart }\end{array}$ & PSI, ARCS coding & Adolescent autonomy undermining behaviour & CDI \\
\hline $\begin{array}{l}\text { Burge \& Hammen } \\
\text { (1991) }\end{array}$ & 57 & $8-16$ & $\begin{array}{l}\text { Longitudinal: T1 and T2 } 6 \\
\text { months apart }\end{array}$ & $\begin{array}{l}5 \text { minute interaction task: } \\
\text { conflict discussion, PIS } \\
\text { coding }\end{array}$ & $\begin{array}{l}\text { Maternal task involvement and negative/critical } \\
\text { feedback }\end{array}$ & K-SADS \\
\hline Corona et al. (2005) & 111 & $\begin{array}{l}\text { Mean } \\
\text { age }= \\
13\end{array}$ & Cross-sectional & $\begin{array}{l}\text { PSI, positive and negative } \\
\text { codes (no coding system } \\
\text { specified) }\end{array}$ & Maternal criticism & $\begin{array}{l}\text { CDI: Short } \\
\text { form }\end{array}$ \\
\hline Dadds et al. (1992) & 73 & $14-17$ & $\begin{array}{l}\text { Cross-sectional: Depressed (18), } \\
\text { conduct disorder (27), mixed } \\
\text { conduct disorder and depression } \\
\text { (12) and controls (16) }\end{array}$ & Evening meal, FOS coding & $\begin{array}{l}\text { Parent and child positive and adverse } \\
\text { behaviours and affect expression }\end{array}$ & K-SADS: EV \\
\hline Dietz et al. (2008) & 112 & $8-17$ & $\begin{array}{l}\text { Longitudinal (21-year } \\
\text { programme): Depressed (43), } \\
\text { high risk (28) and controls (41) }\end{array}$ & $\begin{array}{l}\text { Conflict discussion, FIGCS } \\
\text { coding }\end{array}$ & Maternal disengagement & KSADS:EV \\
\hline Field et al. (1987) & 56 & $4-8$ & $\begin{array}{l}\text { Cross-sectional: } \\
\text { Depressed (20), conduct } \\
\text { disorder (18), controls (18) }\end{array}$ & $\begin{array}{l}\text { Freeplay interaction, teaching } \\
\text { task, solitary freeplay and } \\
\text { child solitary puzzle } \\
\text { completion task (no coding } \\
\text { system specified) }\end{array}$ & Maternal responsiveness to child affect & $\begin{array}{l}\text { DSM-III } \\
\text { diagnosis by } \\
\text { psychiatrist, } \\
\text { CDI }\end{array}$ \\
\hline Gate et al. (2013) & 163 & $12-17$ & $\begin{array}{l}\text { Longitudinal: } \mathrm{T} 1, \mathrm{~T} 2, \mathrm{~T} 32 \\
\text { years between time points }\end{array}$ & $\begin{array}{l}\text { IC, PSI, PES, EPI, LIFE } \\
\text { coding }\end{array}$ & $\begin{array}{l}\text { Maternal aggressive and positive behaviour and } \\
\text { adolescent rumination }\end{array}$ & K-SADS-PL \\
\hline Ge et al. (2004) & 406 & $9-20$ & $\begin{array}{l}\text { Longitudinal: } \mathrm{T} 1, \mathrm{~T} 2, \mathrm{~T} 3, \mathrm{~T} 4 \text { one } \\
\text { year between time points }\end{array}$ & $\begin{array}{l}\text { Discussion of positive and } \\
\text { negative events, coded on } 5 \\
\text { point scale ratings }\end{array}$ & $\begin{array}{l}\text { Parental support (responsiveness, } \\
\text { communication) }\end{array}$ & SCL-90 \\
\hline
\end{tabular}




\begin{tabular}{|c|c|c|c|c|c|c|}
\hline Hamilton et al. (1999) & 59 & $7-14$ & $\begin{array}{l}\text { Cross-sectional: Depressed ( } 21) \text {, } \\
\text { schizophrenia (18) and controls } \\
(20)\end{array}$ & $\begin{array}{l}\text { PSI, Affective Style and } \\
\text { Coping Style coding }\end{array}$ & Parental criticism & K-SADS-E \\
\hline Hofer et al. (2013) & 131 & $13-15$ & $\begin{array}{l}\text { Longitudinal: } \mathrm{T} 1 \text { and } \mathrm{T} 22 \text { years } \\
\text { apart }\end{array}$ & $\begin{array}{l}\text { IC, PSI, affect and verbal } \\
\text { coding }\end{array}$ & Maternal positive affect and anger & CBCL \\
\hline $\begin{array}{l}\text { Hollenstein, Allen and } \\
\text { Sheeber (2015) }\end{array}$ & 84 & $14-18$ & $\begin{array}{l}\text { Cross-sectional: } \\
\text { Depressed (24) and controls } \\
(60)\end{array}$ & EPI, PSI, FCI, LIFE coding & $\begin{array}{l}\text { Affective matching between parents and } \\
\text { adolescents }\end{array}$ & K-SADS \\
\hline Jackson et al. 2011 & 96 & $14-16$ & $\begin{array}{l}\text { Cross-sectional: } \\
\text { Depressed (43), controls (53) }\end{array}$ & IC, PSI, LIFE coding & Parental and adolescent angry behaviour & $\begin{array}{l}\text { K-SADS, CES- } \\
\text { D }\end{array}$ \\
\hline $\begin{array}{l}\text { Jacob \& Johnson } \\
(2001)\end{array}$ & 130 & $10-18$ & Cross-sectional & ACQ, PSI, MICS coding & Parental positivity and positivity suppression & CBCL \\
\hline Jacobvitz et al.(2004) & 108 & $\begin{array}{l}24 \\
\text { months }\end{array}$ & $\begin{array}{l}\text { Longitudinal: } \mathrm{T} 1 \text { and } \mathrm{T} 25 \text { years } \\
\text { apart }\end{array}$ & $\begin{array}{l}\text { Completing unrelated task } \\
\text { whilst providing caregiving, } \\
\text { codes derived using rating } \\
\text { scales }\end{array}$ & Maternal disengagement and role confusion & CBCL \\
\hline Kobak et al (1993) & 48 & $14-18$ & Cross-sectional & $\begin{array}{l}\text { PSI, codes derived using } \\
\text { rating scales }\end{array}$ & Adolescent assertiveness & DDPA \\
\hline Kuppens et al (2010) & 141 & $\begin{array}{l}\text { Mean } \\
\text { age }= \\
16\end{array}$ & $\begin{array}{l}\text { Cross-sectional: } \\
\text { Depressed ( } 72) \text { and controls } \\
\text { (69) }\end{array}$ & $\begin{array}{l}\text { EPI, PSI, discussion of } \\
\text { family life, LIFE coding }\end{array}$ & $\begin{array}{l}\text { Adolescent emotional inertia, angry, dysphoric, } \\
\text { happy behaviour }\end{array}$ & CES-D \\
\hline Kuppens et al (2012) & 165 & $9-12$ & $\begin{array}{l}\text { Longitudinal: T1 and T2 } 2.5 \\
\text { years apart }\end{array}$ & PSI, EPI, LIFE coding & $\begin{array}{l}\text { Adolescent emotional inertia, angry, dysphoric, } \\
\text { happy behaviour }\end{array}$ & $\begin{array}{l}\text { K-SADS-PL, } \\
\text { CES-D }\end{array}$ \\
\hline $\begin{array}{l}\text { Lewandowski \& } \\
\text { Palermo (2009) }\end{array}$ & 30 & $11-16$ & Cross-sectional & IC, PSI, EPI, AIRS coding & $\begin{array}{l}\text { Adolescent age appropriate independence and } \\
\text { responsibility }\end{array}$ & RCADS \\
\hline $\begin{array}{l}\text { Messer \& Gross } \\
(1995)\end{array}$ & 20 & $8-10$ & $\begin{array}{l}\text { Cross-sectional: } \\
\text { High depressive symptoms }(10) \\
\text { and low depressive symptoms } \\
\text { (10) }\end{array}$ & $\begin{array}{l}\text { Home based observation, } \\
\text { codes derived using rating } \\
\text { scales }\end{array}$ & Parent and child positive reciprocal behaviour & CDI \\
\hline $\begin{array}{l}\text { Pavlidis \& McCauley } \\
\text { (2001) }\end{array}$ & 60 & $10-17$ & $\begin{array}{l}\text { Cross-sectional: Depressed (20), } \\
\text { externalising problems }(20) \text { and } \\
\text { controls }(20)\end{array}$ & IC, PSI, ARCS coding & Adolescent autonomy and relatedness & $\begin{array}{l}\text { K-SADS, } \\
\text { CBCL }\end{array}$ \\
\hline
\end{tabular}




\begin{tabular}{|c|c|c|c|c|c|c|}
\hline Pineda et al. (2007) & 72 & $14-18$ & $\begin{array}{l}\text { Cross sectional: } \\
\text { High depressive symptoms (39) } \\
\text { and controls ( } 33 \text { ) }\end{array}$ & $\begin{array}{l}\text { IC, PSI, no coding system } \\
\text { specified }\end{array}$ & $\begin{array}{l}\text { Maternal positive behaviour, and adolescent } \\
\text { depressive behaviour }\end{array}$ & CDI \\
\hline $\begin{array}{l}\text { Sagrestano et al. } \\
(2003)\end{array}$ & 275 & $9-15$ & $\begin{array}{l}\text { Longitudinal: } \mathrm{T} 1 \text { and } \mathrm{T} 22 \text { years } \\
\text { apart }\end{array}$ & $\begin{array}{l}\text { IC, PSI and unfamiliar board } \\
\text { game task, codes derived } \\
\text { using rating scales }\end{array}$ & Parent and child role negotiation & DICA - R \\
\hline Sanders et al. (1992a) & 73 & $7-14$ & $\begin{array}{l}\text { Cross-sectional: Depressed (30), } \\
\text { conduct disorder (27) and } \\
\text { controls (16) }\end{array}$ & IC, PSI, DOS coding & Parent and child angry behaviour & K-SADS, CDI, \\
\hline Schwartz et al. (2011) & 159 & $11-13$ & $\begin{array}{l}\text { Longitudinal: } \mathrm{T} 1 \text { and } \mathrm{T} 2,2-3 \\
\text { years apart }\end{array}$ & $\begin{array}{l}\text { IC, PSI, PES, EPI, LIFE } \\
\text { coding }\end{array}$ & Parental aggressive and dysphoric behaviour & K-SADS-PL \\
\hline Schwartz et al. (2012) & 194 & $10-12$ & $\begin{array}{l}\text { Longitudinal: } \mathrm{T} 1 \text { and } \mathrm{T} 22.5 \\
\text { years apart }\end{array}$ & PSI, PES, EPI, LIFE coding & $\begin{array}{l}\text { Parental aggressive, dysphoric and positive } \\
\text { behaviour }\end{array}$ & $\begin{array}{l}\text { K-SADS, CES- } \\
\text { D, BDI }\end{array}$ \\
\hline Schwartz et al. (2014) & 113 & $10-18$ & $\begin{array}{l}\text { Longitudinal: } \mathrm{T} 1, \mathrm{~T} 2, \mathrm{~T} 3, \mathrm{~T} 42 \\
\text { years between time points }\end{array}$ & $\begin{array}{l}\text { IC, PSI, PEC, EPI, LIFE } \\
\text { coding }\end{array}$ & $\begin{array}{l}\text { Reciprocal maternal and adolescent aggressive, } \\
\text { dysphoric and positive behaviour }\end{array}$ & K-SADS-PL \\
\hline Sheeber et al. (2000) & 50 & $12-19$ & $\begin{array}{l}\text { Cross sectional: Depressed (25) } \\
\text { and controls }(25)\end{array}$ & IC, PSI, LIFE coding & $\begin{array}{l}\text { Parent and adolescent depressive and aggressive } \\
\text { reciprocal behaviour. }\end{array}$ & K-SADS \\
\hline Sheeber et al. (1998) & 494 & $14-18$ & $\begin{array}{l}\text { Longitudinal: } \mathrm{T} 1 \text { and } \mathrm{T} 2 \text { one } \\
\text { year apart } \\
\text { Depressed (86) and controls } \\
(408)\end{array}$ & IC, PSI, LIFE coding & $\begin{array}{l}\text { Parent and adolescent depressive and aggressive } \\
\text { behaviour }\end{array}$ & CBCL-D \\
\hline $\begin{array}{l}\text { Sheeber \& Sorenson } \\
\text { (1998) }\end{array}$ & 52 & $12-19$ & $\begin{array}{l}\text { Cross-sectional: Depressed (26) } \\
\text { and controls (26) }\end{array}$ & IC, PSI, LIFE coding & Maternal aggressive behaviour & K-SADS \\
\hline Sheeber et al. (2009) & 152 & $14-18$ & $\begin{array}{l}\text { Cross-sectional: Depressed (75) } \\
\text { and controls ( } 77)\end{array}$ & $\begin{array}{l}\text { Event planning, conflict } \\
\text { resolution and best and most } \\
\text { difficult memories, LIFE } \\
\text { coding }\end{array}$ & Adolescent angry and dysphoric behaviour & $\begin{array}{l}\text { K-SADS, CES- } \\
\text { D }\end{array}$ \\
\hline Sheeber et al. (2007) & 243 & $14-18$ & $\begin{array}{l}\text { Cross-sectional: Depressed (82), } \\
\text { sub-diagnostic depressive } \\
\text { symptoms (78) and controls } \\
(83)\end{array}$ & IC, PSI, LIFE coding & Parental aversive behaviour & $\begin{array}{l}\text { K-SADS, CES- } \\
\text { D }\end{array}$ \\
\hline
\end{tabular}




\begin{tabular}{|c|c|c|c|c|c|c|}
\hline Sheeber et al. (2012) & 141 & $14-18$ & $\begin{array}{l}\text { Cross-sectional: Depressed (72) } \\
\text { and controls (69) }\end{array}$ & $\begin{array}{l}\text { Family activity task, conflict } \\
\text { task, reminiscence task, LIFE } \\
\text { coding }\end{array}$ & Adolescent angry and dysphoric behaviour & $\begin{array}{l}\text { K-SADS. CES- } \\
\text { D }\end{array}$ \\
\hline $\begin{array}{l}\text { Slesnick \& Waldron } \\
\text { (1997) }\end{array}$ & 37 & $14-16$ & $\begin{array}{l}\text { Cross-sectional: Depressed (17) } \\
\text { and controls (20) }\end{array}$ & ACQ, PSI, LIFE coding & $\begin{array}{l}\text { Parent and adolescent aversive content and } \\
\text { affect, and depressive content and affect }\end{array}$ & CDISC \\
\hline Tompson et al (2012) & 130 & $9-16$ & Cross-sectional & PSI, LIFE coding & Maternal aversive behaviour & CDI \\
\hline $\begin{array}{l}\text { Yap, Allen \& } \\
\text { Ladouceur (2008) }\end{array}$ & 163 & $11-13$ & Cross-sectional & $\begin{array}{l}\text { IC, PSI, PEC, EPI, LIFE } \\
\text { coding }\end{array}$ & $\begin{array}{l}\text { Maternal and adolescent dysphoric and positive } \\
\text { behaviour }\end{array}$ & $\begin{array}{l}\text { CES-D- } \\
\text { Revised }\end{array}$ \\
\hline Yap et al (2010) & 198 & $10-12$ & Cross-sectional & $\begin{array}{l}\text { IC, PSI, PEC, EPI, LIFE } \\
\text { coding }\end{array}$ & $\begin{array}{l}\text { Maternal dysphoric and aversive behaviour, } \\
\text { adolescent emotional regulation and aggressive } \\
\text { behaviour }\end{array}$ & CES-D \\
\hline Yap et al (2011) & 163 & $11-13$ & Cross-sectional & EPI, PSI, LIFE coding & Maternal and adolescent aversive behaviour & CES-D \\
\hline
\end{tabular}

* $N$ includes all participants at follow up for longitudinal studies

$\mathrm{ACQ}=$ Areas of Change Questionnaire, $\mathrm{ARCS}=$ Autonomy and Relatedness Coding System BDI $=$ Beck Depression Inventory, $\mathrm{CBCL}=\mathrm{Child}$ Behaviour Checklist, $\mathrm{CDI}=$ Child Depression Inventory, CDISC $=$ Computerised Diagnostic Interview Schedule for Children, DDPA = Dimensions of Depression Profile for Adolescents, DOS = Depression Observation Schedule, EPI $=$ Event Planning Interaction, FCI $=$ Family Consensus Interaction, FIGCS $=$ Family Interaction Global Coding System, FOS = Family Observation Schedule, IC = Issues Checklist, ISCA = Interview Schedule for Children and Adolescents, K-SADS = Kiddie-Schedule for Affective Disorders and Schizophrenia, K-SADS:EV = Schedule for Affective Disorders and Schizophrenia: Epidemiological Version, K-SADS-PL: Schedule for Affective Disorders and Schizophrenia for School-age Children, Present and Lifetime version, LIFE = Living in Family Environments, MICS = Marital Interaction Coding System, PIS = Peer Interaction System, PES = Pleasant Events Schedule, PS = Problem Solving Interactions, TC = Topics Checklist, VR = Video Recall, YSR $=$ Youth Self Report 